\title{
Local hypocretin-1 modulates terminal dopamine concentration in the nucleus accumbens shell
}

\author{
Robin Patyal ${ }^{\dagger}$, Evan Y. Woo ${ }^{\dagger}$ and Stephanie L. Borgland * \\ Department of Anesthesiology, Pharmacology and Therapeutics, The University of British Columbia, Vancouver, BC, Canada
}

Edited by:

Benjamin Boutrel, Lausanne

University Hospital, Switzerland

Reviewed by:

Mitchell Roitman, University of

Illinois at Chicago, USA

Jonathan Hollander, The Scripps

Research Institute, USA

*Correspondence:

Stephanie L. Borgland, Department

of Anesthesiology, Pharmacology

and Therapeutics, The University of

British Columbia, 212-2176 Health

Sciences Mall, Vancouver,

BC V6T 1Z3, Canada.

e-mail:borgland@mail.ubc.ca

${ }^{\dagger}$ These authors equally contributed

to this work.
Hypocretins (hcrt), also known as orexins, play a critical role in reward-seeking behavior for natural rewards and drugs of abuse. The mesolimbic dopamine pathway that projects from the ventral tegmental area (VTA) to the nucleus accumbens (NAc) is critically involved in the neural mechanisms underlying reward-seeking and motivation. Hcrt immunopositive fibers densely project to the shell of the nucleus accumbens (NAcSh), suggesting that the NAcSh might be a site for the interaction between hcrt and dopaminergic modulation of reward-seeking behavior. While it is known that hort action in the VTA can increase dopamine in the NAc, it has not been determined if hcrt released locally at dopaminergic terminals in the NAcSh can modulate dopamine concentration. Here, we use fast scan cyclic voltammetry (FSCV) in forebrain slices containing the NAcSh to determine whether hcrt can alter evoked dopamine concentration. We found bath application of hcrt-1 increases phasically evoked dopamine release, without altering reuptake at dopamine terminals in the NAcSh. Hcrt-1-induced potentiation of dopamine concentration was inhibited by SB334867, a hcrt receptor 1 antagonist, as well as ionotropic glutamate receptor antagonists, AP-5, CNQX and DNOX. Taken together, these results suggest that local hcrt-1 can modulate dopamine in the NAcSh and may play a role in reward-seeking and appetitive behaviors.

Keywords: hypocretin, orexin, dopamine, nucleus accumbens shell, voltammetry, glutamate

\section{INTRODUCTION}

The hypocretins (hcrt), also known as orexins, are neuropeptides produced solely in the lateral hypothalamic and perifornical areas (de Lecea et al., 1998; Sakurai et al., 1998). They are comprised of two distinct peptides; hypocretin-1 (hcrt-1) and hypocretin-2 (hcrt-2). Hypocretins activate two known G-protein coupled receptors, hcrt receptor 1 (hcrt-R1) and hcrt receptor 2 (hcrt-R2). Hypocretin neurons project locally within the hypothalamus and widely throughout the brain, suggesting hypocretin involvement in multiple physiological functions. Indeed, hypocretin has been implicated in sleep and wakefulness, energy homeostasis and addiction (Aston-Jones et al., 2009; Boutrel et al., 2010).

Dopamine neurons of the ventral tegmental area (VTA) project to the nucleus accumbens (NAc) via the medial forebrain bundle (Nauta et al., 1978). Tonic and phasic activity of dopamine neurons can promote dopamine release in NAc (Tsai et al., 2009). Phasic firing typically accompanies reward-predicting cues leading to reward seeking behaviors (Phillips et al., 2003; Roitman et al., 2004; Day et al., 2007; Tsai et al., 2009). The NAc receives excitatory glutamatergic inputs primarily from cortical and limbic structures, including the hippocampus, basolateral amygdala, prefrontal cortex, and various thalamic nuclei (Sesack et al., 1989; Berendse and Groenewegen, 1990; Callaway et al., 1991; Pennartz et al., 1994; Finch, 1996). While glutamatergic and dopaminergic inputs converge on the same MSNs, direct synaptic contacts between dopaminergic and glutamatergic axon terminals have not been observed in the NAc (Sesack and Pickel, 1990, 1992; O'Donnell and Grace, 1995; Mulder et al., 1998). The NAc consists of two anatomically, biochemically, and behaviorally distinct subregions referred to as the shell (NAcSh) and the core (Meredith et al., 1992, 1993, 2008; Sesack and Grace, 2010). Hypocretin neurons make dense projections to both dopamine neurons of the VTA as well as the medial NAcSh (Peyron et al., 1998; Baldo et al., 2003) where both hcrt-R1 and R2 are expressed (Marcus et al., 2001; Martin et al., 2002).

Many reports have demonstrated that hort- 1 signaling in the VTA promotes reward-seeking behaviors, including reinstatement of extinguished drug seeking behavior (Harris et al., 2005; Wang et al., 2009; James et al., 2011), behavioral sensitization to cocaine (Borgland et al., 2006) or effort for sucrose, high fat or cocaine (España et al., 2010; Thompson and Borgland, 2011). Hcrt-1 increases dopamine neuronal firing (Korotkova et al., 2003; Muschamp et al., 2007; Moorman and Aston-Jones, 2010) and potentiates excitatory synaptic transmission onto dopamine neurons in the VTA (Borgland et al., 2006, 2009), a mechanism thought to promote arousal for salient events (Borgland et al., 2009; Thompson and Borgland, 2011). Hcrt-1 action in the NAcSh inhibits N-methyl-D-aspartate (NMDA)-induced currents in isolated medium neurons (MSNs; Martin et al., 2002). However, other reports suggest that hcrt- 1 or hcrt- 2 dosedependently depolarizes (Mukai et al., 2009) and increases firing rate of MSNs in slices containing the NAcSh (Mukai et al., 2009; Mori et al., 2011). Hcrt-1 administered directly to the NAcSh promotes feeding and locomotor activity (Thorpe and Kotz, 2005) as well as dopamine-dependent turning behavior (Kotani et al., 2008). 
Hcrt-1 in the VTA increases dopamine release in the NAc and prefrontal cortex (Narita et al., 2006; Vittoz and Berridge, 2006; Vittoz et al., 2008; España et al., 2011). Moreover, hcrt-1 in the VTA enhances cocaine-induced dopamine release (España et al., 2011). However, it is unknown if hcrt-1 within the NAcSh can modulate extracellular dopamine concentration $[D A]_{0}$. Here, we tested the hypothesis that hcrt-1 increases evoked $[\mathrm{DA}]_{\mathrm{o}}$ in the NAcSh using Fast Scan Cyclic Voltammetry (FSCV) at single pulse or phasic burst-like stimulation frequencies.

\section{MATERIALS AND METHODS ANIMALS}

All protocols were in accordance with the ethical guidelines established by the Canadian Council for Animal Care and were approved by the University of British Columbia Animal Care Committee. C57BL/6J mice were obtained from the University of British Columbia breeding facility.

\section{SLICE PREPARATION}

Male C57BL/2J mice (25-30 g) were anesthetized with halothane or isoflurane, decapitated, and brains were extracted and prepared for slicing. Coronal slices $(250 \mu \mathrm{m})$ containing the NAcSh were cut in ice-cold sucrose-containing artificial cerebrospinal fluid (aCSF) solution ([mM]: $87 \mathrm{NaCl}, 2.5 \mathrm{KCl}, 1.25$ $\mathrm{NaH}_{2} \mathrm{PO}_{4}, 25 \mathrm{NaHCO}_{3}, 7 \mathrm{MgCl}_{2}, 0.95 \mathrm{CaCl}_{2}, 75$ sucrose) saturated with 95\% $\mathrm{O}_{2} / 5 \% \mathrm{CO}_{2}$ using a vibratome (Leica, Nussloch, Germany). Slices were incubated in warm $\left(31.5^{\circ} \mathrm{C}\right)$ 95\% $\mathrm{O}_{2} / 5 \% \mathrm{CO}_{2}$ oxygenated aCSF ([mM]: $119 \mathrm{NaCl}, 1.6$ $\mathrm{KCl}, 1.0 \mathrm{NaH}_{2} \mathrm{PO}_{4}, 26.2 \mathrm{NaHCO}_{3}, 1.3 \mathrm{MgCl}_{2}, 2.5 \mathrm{CaCl}_{2}$, 11 glucose; $\mathrm{pH}=7.4$ ) for at least $1 \mathrm{~h}$ and transferred to a recording chamber that was constantly perfused (gravity flow: $1.5 \mathrm{ml} / \mathrm{min})$ with oxygenated aCSF $\left(30-32^{\circ} \mathrm{C}\right)$. The slices were allowed to equilibrate in the recording chamber with the superfusion medium for an additional 20-30 min before experimentation.

\section{FAST-SCAN CYCLIC VOLTAMMETRY}

Evoked $[\mathrm{DA}]_{\mathrm{o}}$ was measured using FSCV with carbon-fiber microelectrodes. Carbon fibers ( $7 \mu \mathrm{m}$ diameter; Goodfellow) were pulled in glass electrodes and cut to a final exposed length of $\sim 150 \mu \mathrm{m}$. Triangular waveforms (holding at $-0.4 \mathrm{~V}$ ) at $10 \mathrm{~Hz}$ $(-0.4$ to $1.0 \mathrm{~V}$ vs. $\mathrm{Ag} / \mathrm{AgCl}$ at $400 \mathrm{~V} / \mathrm{s}$ scan rate) were used. Catecholamine release was evoked using electrical stimulation applied with a bipolar stimulating electrode positioned flush with the tissue for local surface stimulation. To evoke $[\mathrm{DA}]_{\mathrm{o}}$ in the NAcSh, either a single pulse was delivered or $100 \mathrm{~Hz}, 5$ pulses to mimic phasic dopamine release (Rice and Cragg, 2004). The voltammetric electrode was positioned between the tips with the aid of a binocular microscope, and then lowered 50-100 $\mu \mathrm{m}$ into the tissue. Dopamine was identified by characteristic oxidation and reduction peak potentials (approx. +600 and $-200 \mathrm{mV}$ vs. $\mathrm{Ag} / \mathrm{AgCl}$ ). To determine the time course of dopamine, the current at the peak oxidation was plotted against time. Relative electrode sensitivities for dopamine were determined by obtaining voltammograms from exogenous application of dopamine $(0.1-1 \mu \mathrm{M})$ made from stock solutions in $0.1 \mathrm{M} \mathrm{HClO}_{4}$ immediately before use.

\section{DRUGS}

Hcrt-1 or AP-5 was purchased from Tocris (Ellisville), reconstituted in $\mathrm{ddH}_{2} \mathrm{O}$ and stored in aliquots at $-20^{\circ} \mathrm{C}$. Ten minutes prior to drug application aliquots were thawed and diluted to the working concentration in aCSF buffer. CNQX or DNQX was purchased from Sigma (Oakville) reconstituted in DMSO and stored in aliquots, protected from light, at $-20^{\circ} \mathrm{C}$. Prior to the experiment, these compounds were diluted in aCSF and used at 1/1000 working concentrations of DMSO. SB334867 was purchased from Tocris (Ellisville) reconstituted in DMSO and stored in aliquots at $-20^{\circ} \mathrm{C}$. Prior to the experiment, SB334867 was diluted in aCSF and used at $1 / 1000$ working concentrations of DMSO. Our previous work has demonstrated that 1/1000 DMSO does not influence evoked $[\mathrm{DA}]_{\mathrm{o}}$ (Mebel et al., 2012).

\section{STATISTICS}

Values listed are means \pm SEM. Statistical significance was assessed using a paired student $t$-test comparing a time-point on the baseline prior to drug application to a time-point after drug application. For multiple comparisons, One-Way ANOVA was used unless otherwise indicated. A difference of $p<0.05$ was considered significant. Statistical tests were performed with GraphPad Prism v.5.

\section{RESULTS}

\section{Hcrt-1 DOES NOT MODIFY SINGLE PULSE EVOKED [DA] A AT TERMINALS}

To determine if hcrt-1 could modulate $[\mathrm{DA}]_{\mathrm{o}}$ at dopaminergic terminals in the NAcSh where there is significant density of hortimmunopositive axonal fibers (Baldo et al., 2003), we applied hcrt-1 (100 nM) for $5 \mathrm{~min}$ to slices while evoking dopamine with a single pulse every $2 \mathrm{~min}$. Hcrt-1 did not significantly alter the oxidation potential of dopamine (Figure 1A) or the maximal release of dopamine (Figure 1B; baseline: $101 \pm 3 \%$ vs. $15 \mathrm{~min}$ after hcrt-1: $96 \pm 4 \%, n=7 ; P>0.05)$. No significant change occurred in evoked $[\mathrm{DA}]_{\mathrm{o}}$ over the duration of the experiment in the absence of hcrt-1 (Figure 1B; baseline: $96 \pm 3 \%$ vs: $15 \mathrm{~min}$ after vehicle aCSF application: $95 \pm 7 \%, n=5 ; P>0.05)$. The decay of the current, represented by tau $(\tau)$, has been demonstrated to be positively correlated with $K_{m}$, suggesting that $\tau$ is an appropriate measurement of dopamine uptake (Yorgason et al., 2011). Averaged current-time plots of evoked [DA $]_{\mathrm{o}}$ indicated that hcrt-1 did not significantly modify dopamine uptake under single pulse conditions (Figures 1C,D, $\tau_{\text {baseline }}=0.41 \pm$ $\left.0.05 \mathrm{~s}, \tau_{\text {hcrt }-1}=0.43 \pm 0.05 \mathrm{~s} ; n=7 ; P>0.05\right)$. Decay of evoked dopamine did not significantly change over the course of the experiment in the absence of hcrt-1 ( $\tau_{\text {baseline }}=0.44 \pm 0.09 \mathrm{~s}$, $\left.\tau_{\mathrm{aCSF}}=0.41 \pm 0.07 \mathrm{~s} ; n=5 ; P>0.05\right)$.

\section{Hcrt-1 INCREASES PHASIC [DA] o AT TERMINALS}

Phasic dopamine release accompanies reward-predicting stimuli (Phillips et al., 2003; Roitman et al., 2004; Day et al., 2007). To test if hcrt-1 was able to modulate terminal $[\mathrm{DA}]_{\mathrm{o}}$ under phasic conditions, we evoked dopamine release every $5 \mathrm{~min}$ with $100 \mathrm{~Hz}$, 5 pulses, a parameter which increases dopamine concentration relative to a single pulse (Rice and Cragg, 2004). As reported previously, we observed an 5.5 fold increase in $[\mathrm{DA}]_{\mathrm{o}}$ with phasic 


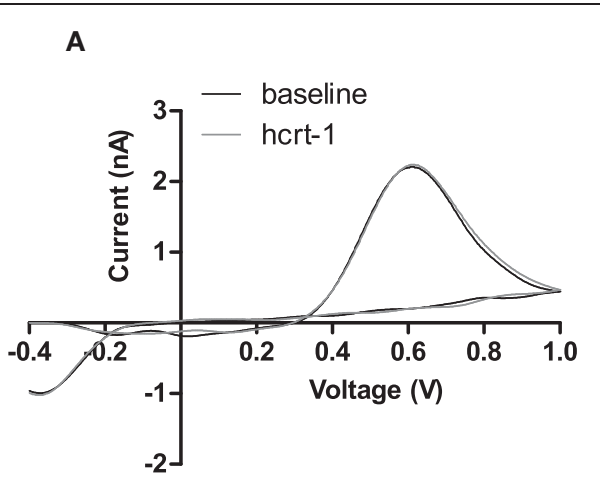

C

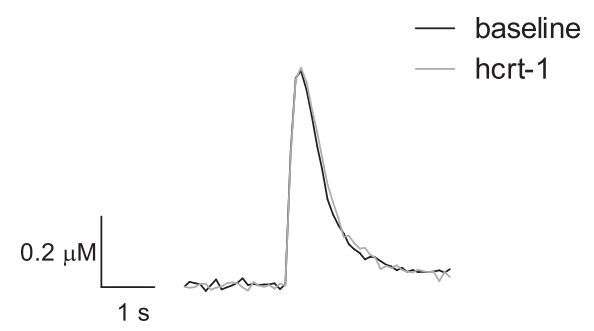

FIGURE 1 | Hcrt-1 does not modify single pulse dopamine in the NAcSh. $[D A]_{\circ}$ was electrically evoked using a single pulse in slices containing the NAcSh. (A) An example voltammogram from a single experiment for electrically evoked [DA] before (black line) and immediately after a $5 \mathrm{~min}$ hcrt-1 (100 nM, grey line) application. (B) Bath application of hcrt-1 (100 nM, $5 \mathrm{~min}$, filled circles) did not modify evoked [DA] in NAcSh slices $(n=6)$ compared to control slices $(n=5$, open circles) $(P<0.05)$. (C) A

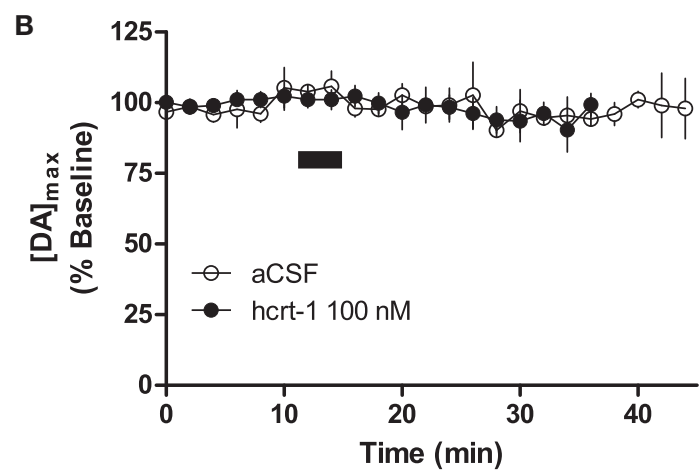

D

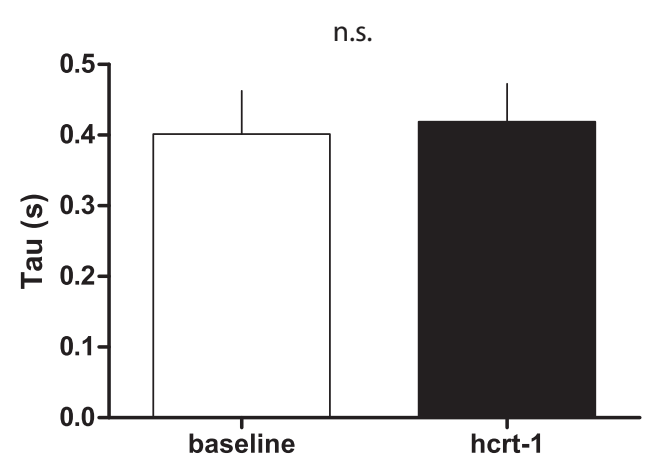

representative current-time plot from a single experiment showing [DA] evoked before (open black line) and 15 min after (grey line) application of hcrt-1 (100 nM). (D) The signal decay was fit with a one phase exponential curve to determine the rate of decay 5 min before and 15 min after immediately after hcrt-1 application. The rate of decay, Tau $(\tau)$, before and after hcrt-1 application was not significantly different $(P>0.05, n=6)$. Bars represent mean and SEM. stimulation $(4.2 \pm 1.6 \mu \mathrm{M}, n=13)$ compared to a single pulse (0.8 $\pm 0.2 \mu \mathrm{M}, n=6$; Patel et al., 1992; Rice and Cragg, 2004). Interestingly, hcrt-1 increased $[\mathrm{DA}]_{\mathrm{o}}$ in NAcSh slices with a slow time course, reaching a maximum at $25 \mathrm{~min}$ after hcrt-1 application (Figures 2A,B,C, baseline: $99 \pm 2 \%$ vs. $25 \mathrm{~min}$ after hcrt-1: $137 \pm 12 \%, n=10, P<0.05)$. To test if peak $[\mathrm{DA}]_{\mathrm{o}}$ was altered during hcrt-1 application, we evoked $[\mathrm{DA}]_{\mathrm{o}} 2.5 \mathrm{~min}$ after initiation of the $5 \mathrm{~min}$ bath application. Surprisingly, there was no significant increase in phasically evoked $[\mathrm{DA}]_{\mathrm{o}}$ immediately after hcrt-1 application (baseline: $99 \pm 4$ vs. hcrt-1: $108 \pm 5 \%, n=5$, $P>0.05)$. To determine if the increase in $[\mathrm{DA}]_{\mathrm{o}}$ was due to a change in uptake, we measured the decay of evoked DA under phasic conditions. There was no significant difference in $\tau 25 \mathrm{~min}$ after application of hcrt-1 (Figure 2D, $\tau_{\text {baseline }}=0.46 \pm 0.05 \mathrm{~s}$, $\left.\tau_{\text {hcrt }-1}=0.53 \pm 0.07 \mathrm{~s} ; n=10 ; P>0.05\right)$. Taken together, these results suggest that hcrt-1 increases dopamine release only under phasic release conditions.

To determine if hcrt-1-induced potentiation of striatal $[\mathrm{DA}]_{\mathrm{o}}$ required activation of hcrt-R1, we applied hcrt-1 in the presence of the hcrt-R1 antagonist, SB334867 (1 $\mu \mathrm{M})$ while evoking $[\mathrm{DA}]_{\mathrm{o}}$ under phasic conditions. In slices preincubated for $30 \mathrm{~min}$ with SB334867, hcrt-1 did not alter phasically evoked [DA]
(Figures 3A,B, immediately prior to hcrt-1: $97 \pm 2 \%$; 25 min after hcrt-1 application: $94 \pm 3 \%, n=4, P>0.05$ ), suggesting that striatal hcrt-R1s are required for hort-1-mediated potentiation of $[\mathrm{DA}]_{\mathrm{o}}$.

Interestingly, hcrt-1 modulation of dopamine release occurs only under phasic conditions and not single pulse, suggesting that hort-1 may not be directly modulating dopamine terminals to promote release. One possibility is that hort-1 could be acting at its receptors on glutamatergic terminals within the NAcSh to increase dopamine release indirectly. To test the contribution of glutamatergic signaling to hcrt-1 modulation of $[\mathrm{DA}]_{\mathrm{o}}$ in the NAcSh, we repeated the experiment in the presence of CNQX $(10 \mu \mathrm{M})$ and AP-5 $(50 \mu \mathrm{M})$ to block $\alpha$-amino-3-hydroxy5-methylisoxazole-4-propionate (AMPA)/Kainate and NMDA receptors, respectively. Application of excitatory amino acid receptor antagonists significantly attenuated phasically evoked dopamine by $12 \pm 4 \%$ (Figures 4A,B,C; baseline: $100 \pm 2 \%$ vs. CNQX/AP-5: $89 \pm 4 \%, n=6, P<0.05)$. The effect of hcrt-1 on $[\mathrm{DA}]_{\mathrm{o}}$ was abolished in the presence of CNQX and AP5 (Figures 4A,B,C, $25 \mathrm{~min}$ after hcrt-1 application: $91 \pm 4 \%$, $n=6, P>0.05)$. Application of the AMPA/Kainate receptor antagonist, DNQX, inhibited phasically evoked dopamine by 


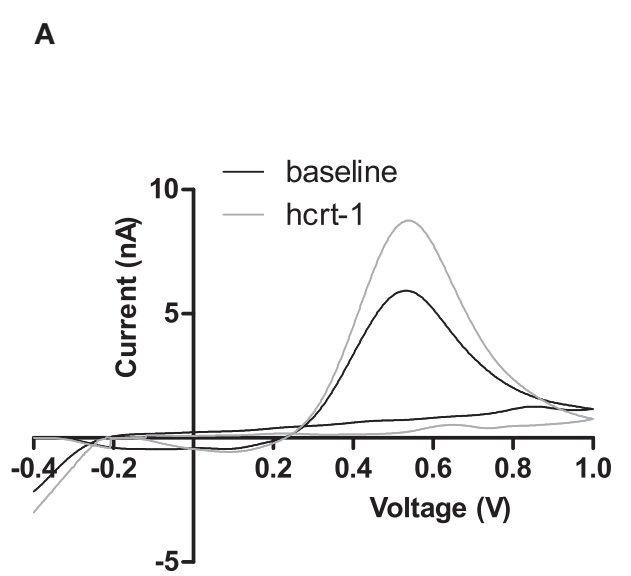

C

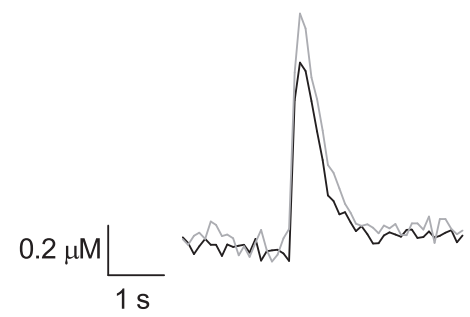

FIGURE 2 | Hcrt-1 increases phasic dopamine in the NAcSh. Phasic [DA]。 was electrically evoked using $100 \mathrm{~Hz}, 5$ pulses in slices containing the NAcSh. (A) An example voltammogram from a single experiment for electrically evoked [DA] o before (black line) and immediately after a 5 min hcrt-1 (100 nM, grey line) application. (B) Bath application of hcrt-1 (100 nM, 5 min, filled circles) significantly increased evoked [DA] in NAcSh slices $(n=11)$ compared to control slices ( $n=6$, open circles) $(* P<0.05)$. (C) A

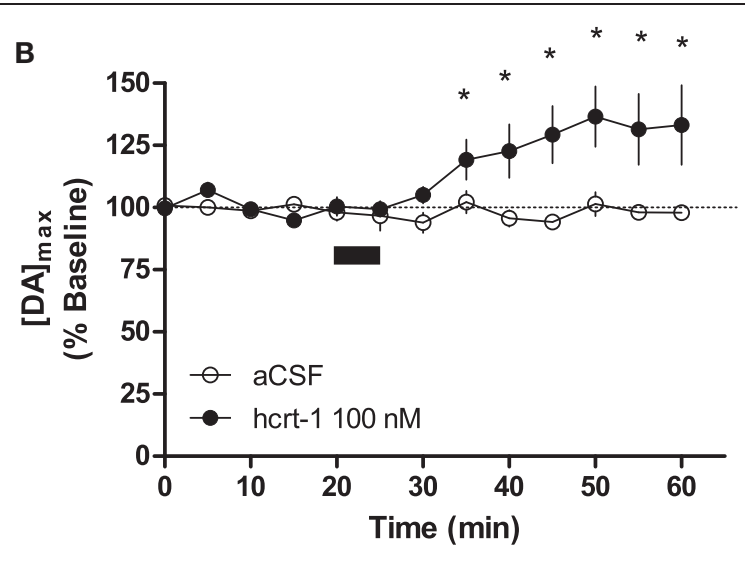

D

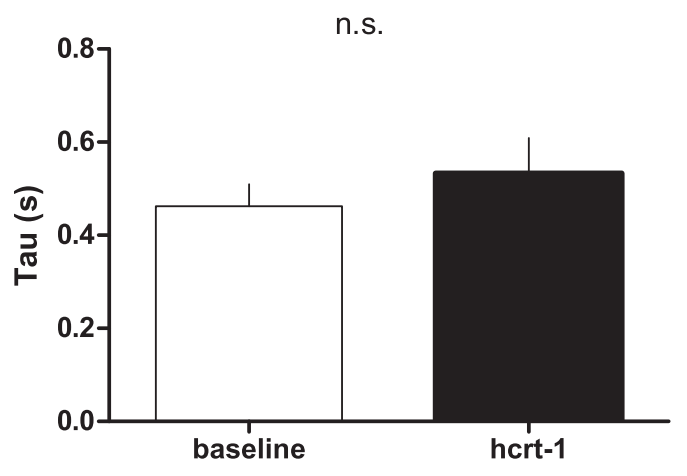

representative current-time plot from a single experiment showing $[D A]_{\circ}$ evoked before (open black line) and 25 min after (grey line) application of hcrt-1 (100 nM). (D) The signal decay was fit with a one phase exponential curve to determine the rate of decay 5 min before and 25 min after immediately after hcrt-1 application. Tau before and after hcrt-1 application was not significantly different $(P>0.05, n=11)$. Bars represent mean and SEM.
A

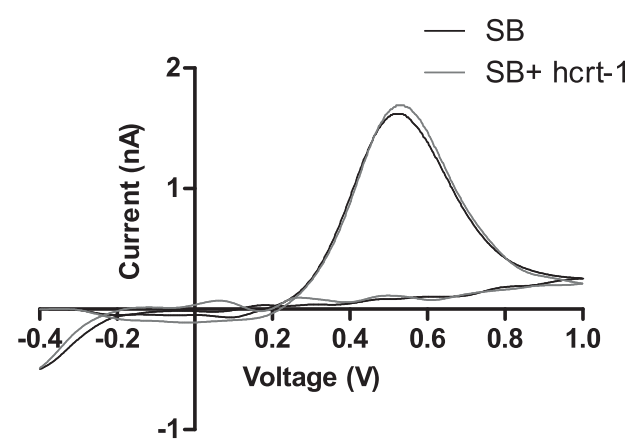

FIGURE 3 | Hcrt-1 modulation of phasic dopamine in the NAcSh is mediated by hcrt-R1. Phasic $[D A]_{\circ}$ was electrically evoked using $100 \mathrm{~Hz}, 5$ pulses in slices containing the NAcSh. Slices were preincubated with SB $334967(1 \mu \mathrm{M})$ for $30 \mathrm{~min}$ prior to application of hcrt-1 and throughout the experiment. (A) An example
B

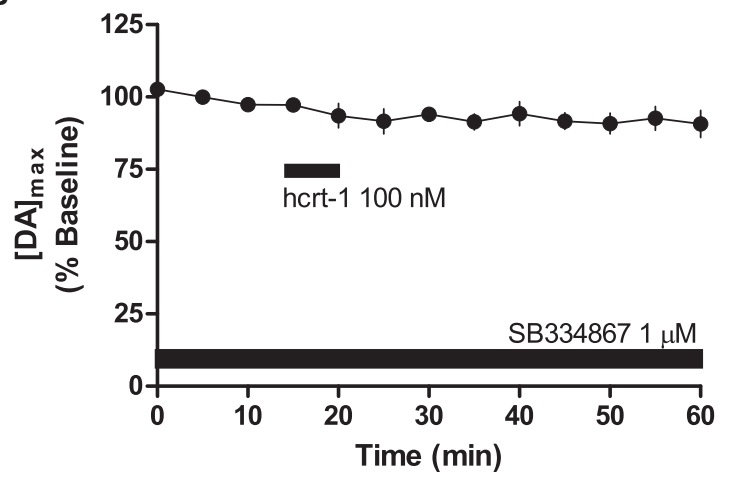

voltammogram from a single experiment for electrically evoked [DA]。 before (black line) and 25 min after a 5 min hcrt-1 (100 nM, grey line) application. (B) In the presence of SB 334867, bath application of hcrt-1 (100 nM, $5 \mathrm{~min}$ ) did not significantly alter evoked [DA $]_{0}$ in NAcSh slices $(n=4 ; P>0.05)$. 


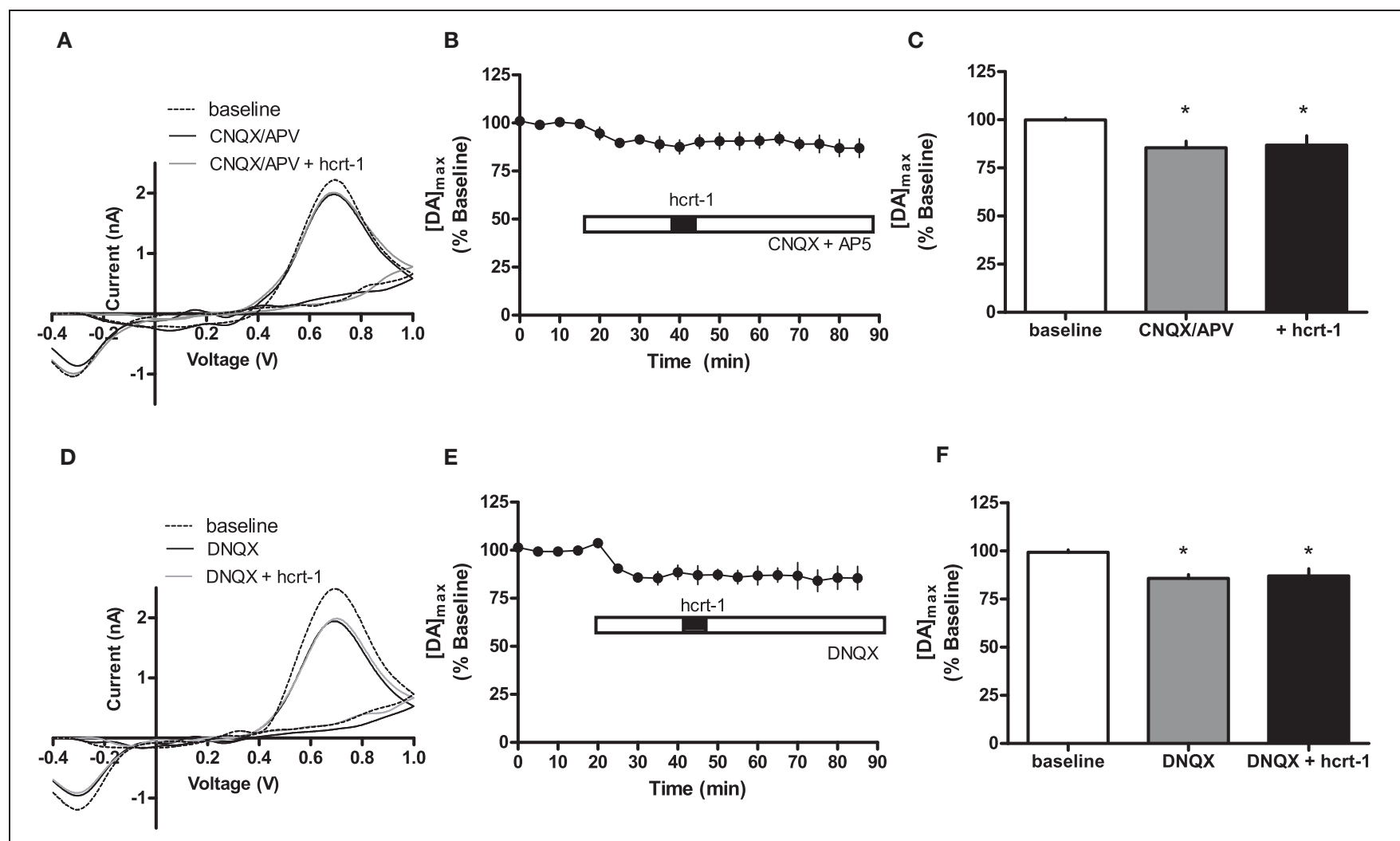

FIGURE 4 | Hcrt-1 modulation of phasic dopamine in the NAcSh requires glutamatergic signaling. Phasic [DA] was electrically evoked using $100 \mathrm{~Hz}$, 5 pulses in slices containing the NAcSh. (A) CNOX (10 $\mu \mathrm{M})$ and AP5 (50 $\mu \mathrm{M})$ were bath applied to slices for 20 min prior to application of hcrt-1 and throughout the experiment. An example voltammogram from a single experiment for electrically evoked [DA] before (hatched line), during CNQX and AP5 treatment (black line) and 25 min after a 5 min hcrt-1 (100 nM, grey line) application. (B) CNOX and AP5 significantly reduced [DA] $]_{\circ}$ in NAcSh slices $(P<0.05)$. In the presence of CNQX and AP5, bath application of hcrt-1 (100 nM, $5 \mathrm{~min}$ ) did not significantly alter evoked [DA $]_{0}$ in NAcSh slices ( $n=7$; $P>0.05)$. (C) A bargraph demonstrating maximal effects relative to baseline (open bar) of CNOX and AP5 treatment with (filled bar) or without hcrt-1 (shaded bar). CNOX and AP5 with or without hcrt-1 was significantly different from baseline (repeated measures ANOVA with a tukey's post hoc test $n=7$; $P<0$.05). (D) An example voltammogram from a single experiment for electrically evoked $[D A]_{0}$ before (hatch line), during DNOX treatment (black line) and $25 \mathrm{~min}$ after a $5 \mathrm{~min}$ hcrt-1 (100 nM, grey line) application. (E) DNQX significantly reduced $[\mathrm{DA}]_{0}$ in NAcSh slices $(P<0.05)$. In the presence of DNQX, bath application of hcrt-1 (100 nM, $5 \mathrm{~min})$ did not significantly alter evoked $[D A]_{0}$ in NAcSh slices ( $\left.n=5 ; P>0.05\right)$. (F) A bar graph demonstrating maximal effects relative to baseline (open bar) of DNQX treatment with (filled bar) or without hcrt-1 (shaded bar). DNQX with or without hcrt-1 was significantly different from baseline (repeated measures ANOVA with a tukey's post hoc test $(n=5 ; P<0.05)$. Bars represent means and SEM. ${ }^{*} p<0.05$.
$14 \pm 2 \%$ (Figures 4D,E,F; baseline: $100 \pm 1 \%$ vs. DNQX: $85 \pm$ $4 \%, n=5, P<0.05)$. The effect of hcrt-1 on $[\mathrm{DA}]_{\mathrm{o}}$ was also abolished in the presence of DNQX (Figures 4D,E,F; 25 min after hcrt-1 application: $87 \pm 5 \%, n=5, P>0.05)$. Taken together, these data suggest that hort- 1 activation of glutamatergic inputs is required for hcrt-1-mediated increase in dopamine release under phasic conditions.

\section{DISCUSSION}

While several studies have demonstrated that hort-1 administered into the VTA can increase dopamine concentration in the NAcSh (Vittoz et al., 2008), NAc core (España et al., 2011) or both (Narita et al., 2006), our data suggests an additional mechanism by which hcrt-1 can modulate dopamine concentrations in the NAcSh. We demonstrate that hcrt-1 promotes local dopamine release in NAcSh slices, suggesting that direct projections of hcrt neurons from the lateral hypothalamus can modulate dopamine release onto medium spiny neurons of the
NAcSh. Notably hcrt-1-induced increase of $[D A]_{o}$ under phasic conditions reached a maximum 15 after hcrt-1 application. This delayed effect is likely due to the necessity for the 33 amino acid peptide to penetrate the tissue to reach its receptors. Interestingly, hcrt-1 modulates NMDA receptors on VTA dopamine neurons with a similar time course (Borgland et al., 2006). Hcrt-1 potentiation of local $[\mathrm{DA}]_{\mathrm{o}}$ was due to an increase in dopamine release as opposed to modulation of reuptake mechanisms as there was no effect of hcrt-1 on the decay of evoked dopamine. Taken together, in addition to hcrt- 1 acting at the VTA to increase dopamine concentration in the NAc, hcrt-1 can also act at terminals to modulate release.

We observed that hcrt-1 modulated evoked $[\mathrm{DA}]_{\mathrm{o}}$ under phasic conditions, but not after a single pulse repeated every 2 min. Therefore, it is likely that hcrt-1 is acting indirectly in the NAcSh to increase terminal dopamine release. One possibility is that hcrt-1 modulates GABAergic activity onto dopamine terminals in the NAcSh. While it has not been demonstrated how dopamine 
concentration is modulated by GABA in the NAcSh, GABA is reported to increase $[\mathrm{DA}]_{\mathrm{o}}$ in the dorsal striatum (Avshalumov et al., 2003). Alternatively, hcrt-1 may act on glutamatergic inputs in the NAcSh to modulate $[\mathrm{DA}]_{\mathrm{o}}$. Consistent with this idea, we demonstrated that application of AMPA or NMDA receptor antagonists inhibited a hcrt-1-induced increase of $[\mathrm{DA}]_{\mathrm{o}}$.

Dopamine spillover from dopaminergic synapses onto MSNs not only activates receptors on MSNs several micrometers away (Garris et al., 1994; Gonon, 1997; Gonon et al., 2000), but may also activate presynaptic dopamine receptors on neighboring glutamatergic afferents (Wang and Pickel, 2002). Furthermore, glutamate released from excitatory inputs in the NAc can also modulate dopamine release, although its effects are complicated by the heterogeneity of expression and location of ionotropic and metabotropic glutamate receptors. There is a large body of evidence suggesting that glutamate is excitatory toward dopamine release (Cheramy et al., 1986; Clow and Jhamandas, 1988; Kalivas et al., 1989; Leviel et al., 1990; Carrozza et al., 1992; Desce et al., 1992; Jin and Fredholm, 1997; Borland and Michael, 2004). However, these studies mainly employ use of microdialysis techniques or dopamine release from isolated cells or synaptosomes. Using FSCV in NAcSh slices, we demonstrate that application of ionotropic glutamate receptor antagonists, AP-5 and CNQX or DNQX alone, significantly inhibited phasically evoked $[\mathrm{DA}]_{\mathrm{o}}$. In contrast to the present study, phasically evoked dopamine from dorsal striatum slices was increased in the presence of the AMPA receptor antagonist, GYKI-52466 (Avshalumov et al., 2003, 2008), the NMDA receptor antagonist, AP-5 or the broad spectrum ionotropic glutamate receptor antagonist, kynurenate (Wu et al., 2000). Moreover, glutamate spillover can activate metabotropic glutamate receptors to inhibit evoked dopamine (Zhang and Sulzer, 2003). A possible reason for the discrepancy between our study and the other studies employing FSCV in slices is that the distribution of ionotropic receptors and glutamatergic inputs may differ between dorsal striatum and NAcSh (Pennartz et al., 1994; Sesack and Grace, 2010). Indeed, NMDA or AMPA receptors increase dopamine efflux in a study employing in vivo voltammetry in the NAc (Svensson et al., 1994) and that DNQX can inhibit quisqualate evoked dopamine concentration in a study employing microdialysis in the NAc (Imperato et al., 1990).

Hcrt-1 acts with similar efficacy at both hcrt-R1 and hcrtR2 (Sakurai et al., 1998). Because hcrt-1 has been implicated in addiction-related behaviors and modulation of dopamine via its action in the VTA, we were interested in testing if this peptide altered local dopamine release at axon terminals. Interestingly, the hcrt-1-mediated increase in NAcSh dopamine was inhibited

\section{REFERENCES}

Aston-Jones, G., Smith, R. J., Moorman, D. E., and Richardson, K. A. (2009). Role of lateral hypothalamic orexin neurons in reward processing and addiction. Neuropharmacology 56(Suppl. 1), 112-121.

Avshalumov, M. V., Chen, B.

T., Marshall, S. P., Peña, D.

M., and Rice, M. E. (2003).

by SB 334867, suggesting this effect was mediated by hcrt-R1. Hcrt-R2, and to a lesser extent hort-R1 are expressed within the NAcSh (Trivedi et al., 1998; Marcus et al., 2001; Martin et al., 2002). Notably, cell bodies of glutamatergic neuron that project to the NAcSh, including the prefrontal cortex and basolateral amydala, express hcrt-R1 (Trivedi et al., 1998; Lu et al., 2000; Marcus et al., 2001) and it is possible that their axon terminals may also express hcrt-R1. Furthermore, hcrt-1 promotion of glutamate release has been demonstrated in other brain regions such as the VTA (Borgland et al., 2006, 2009; Wang et al., 2009), amygdala (John et al., 2003) and hippocampus (Stanley and Fadel, 2011). Therefore, it is feasible that activation of hcrt-R1s on glutamatergic inputs in the NAcSh can increase glutamate release. Our results support the possibility that hort-R1 activation on glutamatergic inputs can promote dopamine release in the NAcSh.

Dense staining of hort terminals in the NAcSh has been observed (Peyron et al., 1998; Baldo et al., 2003), suggesting that hort-1 has direct action in the NAc. Local action of hcrt-1 at dopaminergic terminals may potentiate effects of hcrt-1-mediated dopamine release via its action in the VTA. Indeed, other studies have demonstrated that application of hcrt- 1 or hcrt- 2 into the NAcSh can potentiate dopaminergic activity. For example, in NAcSh slices, when hcrt-2 was co-applied with dopamine, its effect on firing rate was significantly potentiated in $2 / 3$ of MSNs when compared to hcrt-2-induced or dopamine-induced firing alone (Mori et al., 2011). Another study demonstrated that hcrt-1 or hcrt-2 administered directly in the NAcSh potentiated the effects of dopamine receptor agonists on contraversive pivoting behavior (Kotani et al., 2008). Thus, consistent with our study, it is likely that an interaction between hcrt and dopaminergic systems for reward seeking behavior may occur in the NAcSh. Furthermore, one can speculate that local action of hcrt-1 in the NAcSh may potentiate dopaminergic responses mediated by hcrt-1 or other drug action in the VTA. In summary, hcrt-1 increased phasically evoked $[\mathrm{DA}]_{\mathrm{o}}$ in the NAcSh. This effect required activation of AMPA receptors and hcrt-R1. This study demonstrates an additional mechanism by which hcrt-1 can modulate dopamine release and potentially influence appetitive behaviors.

\section{ACKNOWLEDGMENTS}

This work was supported by an NSERC discovery grant and a CIHR New Investigator Award to Stephanie L. Borgland as well as an NSERC undergraduate summer research studentship to Evan Y. Woo.

dopamine release. J. Neurophysiol. 100, 1590-1601.

Baldo, B. A., Daniel, R. A., Berridge, C. W., and Kelley, A. E. (2003). Overlapping distributions of orexin/hypocretin- and dopaminebeta-hydroxylase immunoreactive fibers in rat brain regions mediating arousal, motivation, and stress. J. Comp. Neurol. 464, 220-237.
Berendse, H. W., and Groenewegen, H. J. (1990). Organization of the thalamostriatal projections in the rat, with special emphasis on the ventral striatum. J. Comp. Neurol. 299, 187-228.

Borgland, S. L., Taha, S. A., Sarti, F., Fields, H. L., and Bonci, A. (2006). Orexin A in the VTA is critical for the induction of synaptic plasticity and behavioral 
sensitization to cocaine. Neuron 49, 589-601.

Borgland, S. L., Chang, S. J., Bowers, M. S., Thompson, J. L., Vittoz, N., Floresco, S. B., et al. (2009). Orexin A/hypocretin-1 selectively promotes motivation for positive reinforcers. J. Neurosci. 29, 11215-11225.

Borland, L. M., and Michael, A. C. (2004). Voltammetric study of the control of striatal dopamine release by glutamate. J. Neurochem. 91, 220-229.

Boutrel, B., Cannella, N., and de Lecea, L. (2010). The role of hypocretin in driving arousal and goal-oriented behaviors. Brain Res. 1314, 103-111.

Callaway, C. W., Hakan, R. L., and Henriksen, S. J. (1991). Distribution of amygdala input to the nucleus accumbens septi: an electrophysiological investigation. J. Neural. Transm. 83, 215-225.

Carrozza, D. P., Ferraro, T. N., Golden, G. T., Reyes, P. F., and Hare, T. A. (1992). In vivo modulation of excitatory amino acid receptors: microdialysis studies on $\mathrm{N}$ methyl-d-aspartate-evoked striatal dopamine release and effects of antagonists. Brain Res. 574, 42-48.

Cheramy, A., Romo, R., Godeheu, G., Baruch, P., and Glowinski, J. (1986). In vivo presynaptic control of dopamine release in the cat caudate nucleus-II. Facilitatory or inhibitory influence of l-glutamate. Neuroscience 19, 1081-1090.

Clow, D. W., and Jhamandas, K. (1988). Characterization of 1glutamate action on the release of endogenous dopamine from the rat caudate-putamen. J. Pharmac. Exp. Ther. 248, 722-728.

Day, J. J., Roitman, M. F., Wightman, R. M., and Carelli, R. M. (2007). Associative learning mediates dynamic shifts in dopamine signaling in the nucleus accumbens. Nat. Neurosci. 10, 1020-1028.

de Lecea, L., Kilduff, T. S., Peyron, C., Gao, X., Foye, P. E., Danielson, P. E., et al. (1998). The hypocretins: hypothalamus-specific peptides with neuroexcitatory activity. Proc. Natl. Acad. Sci. U.S.A. 95, 322-327.

Desce, J. M., Godeheu, G., Galli, T., Artaud, F., Cheramy, A., and Glowinski, J. (1992). l-glutamateevoked release of dopamine from synaptosomes of the rat striatum: involvement of AMPA and $N$-methyl-d-aspartate receptors. Neuroscience 47, 333-339.

España, R. A., Oleson, E. B., Locke, J. L., Brookshire, B. R., Roberts, D. C. S., and Jones, S. R. (2010). The hypocretin-orexin system regulates cocaine self-administration via actions on the mesolimbic dopamine system. Eur. J. Neurosci. 31, 336-348.

España, R. A., Melchior, J. R., Roberts, D. C. S., and Jones, S. R. (2011). Hypocretin 1/orexin A in the ventral tegmental area enhances dopamine responses to cocaine and promotes cocaine self-administration. Psychopharmacology 214, 1-12.

Finch, D. M. (1996). Neurophysiology of converging synaptic inputs from the rat prefrontal cortex, amygdala, midline thalamus, and hippocampal formation onto single neurons of the caudate/putamen and nucleus accumbens. Hippocampus 6, 495-512.

Garris, P. A., Ciolkowski, E. L., Pastore, P., and Wightman, R. M. (1994). Efflux of dopamine from the synaptic cleft in the nucleus accumbens of the rat brain. J. Neurosci. 14, 6084-6093.

Gonon, F. (1997). Prolonged and extrasynaptic excitatory action of dopamine mediated by $D_{1}$ receptors in the rat striatum in vivo. J. Neurosci. 17, 5972-5978.

Gonon, F., Burie, J. B., Jaber, M., Benoit-Marand, M., Dumartin, B. and Bloch, B. (2000). Geometry and kinetics of dopaminergic transmission in the rat striatum and in mice lacking the dopamine transporter. Prog. Brain. Res. 125, 291-302.

Harris, G. C., Wimmer, M., and AstonJones, G. (2005). A role for lateral hypothalamic orexin neurons in reward seeking. Nature 437, 556-559.

Imperato, J., Honore, T., and Jensen, L. H. (1990). Dopamine release in the nucleus caudatus and in the nucleus accumbens is under glutamatergic control through non-NMDA receptors: a study in freely-moving rats. Brain Res. 530, 223-228.

James, M. H., Charnley, J. L., Levi, E. M., Jones, E., Yeoh, J. W., Smith, D. W., et al. (2011). Orexin1 receptor signalling within the ventral tegmental area, but not the paraventricular thalamus, is critical to regulating cue-induced reinstatement of cocaine-seeking. Int. J. Neuropsychopharmacol. 14, 684-690.

Jin, S., and Fredholm, B. B. (1997). Electrically-evoked dopamine and acetylcholine release from rat striatal slices perfused without magnesium: regulation by glutamate acting on NMDA receptors. $\mathrm{Br}$. J. Pharmac. 121, 1269-1276.

John, J., Wu, M. F., Kodama, T., and Siegel, J. M. (2003). Intravenously administered hypocretin-1 alters brain amino acid release: an in vivo microdialysis study in rats. J. Physiol. 548, 557-562.

Kalivas, P. W., Duffy, P., and Barrow, J. (1989). Regulation of the mesocorticolimbic dopamine system by glutamic acid receptor subtypes. J. Pharmac. Exp. Ther. 251, 378-388.

Korotkova, T. M., Sergeeva, O. A. Eriksson, K. S., Haas, H. L., and Brown, R. E. (2003). Excitation of ventral tegmental area dopaminergic and nondopaminergic neurons by orexins/hypocretins. J. Neurosci. 23, 7-11.

Kotani, A., Ikeda, H., Koshikawa, N. and Cools, A. R. (2008). Orexin A in the nucleus accumbens stimulates feeding and locomotor activity. Neuropharmacology 54, 613-619.

Leviel, V., Gobert, A., and Guibert, B. (1990). The glutamate-mediated release of dopamine in the rat striatum: further characterization of the dual excitatory-inhibitory function. Neuroscience 39, 305-312.

Lu, X. Y., Bagnol, D., Burke, S., Akil, H., and Watson, S. J. (2000). Differential distribution and regulation of $\mathrm{OX} 1$ and $\mathrm{OX} 2$ orexin/hypocretin receptor messenger RNA in the brain upon fasting. Horm. Behav. 37, 335-344.

Marcus, J. N., Aschkenasi, C. J., Lee, C. E., Chemelli, R. M., Saper, C. B., Yanagisawa, M., et al. (2001). Differential expression of orexin receptors 1 and 2 in the rat brain. J. Comp. Neurol. 435, 6-25.

Martin, G., Fabre, V., Siggins, G. R. and de Lecea, L. (2002). Interaction of the hypocretins with neurotransmitters in the nucleus accumbens. Regul. Pept. 104, 111-117.

Mebel, D. M., Wong, J. C., Dong, Y. J., and Borgland, S. L. (2012). Insulin in the ventral tegmental area reduces hedonic feeding and suppresses dopamine concentration via increased reuptake. Eur. J. Neurosci. 36, 2336-2346.

Meredith, G. E., Agolia, R., Arts, M. P., Groenewegen, H. J., and Zahm, D. S. (1992). Morphological differences between projection neurons of the core and shell in the nucleus accumbens of the rat. Neuroscience 50, 149-162.

Meredith, G. E., Baldo, B. A., Andrezjewski, M. E., and Kelley, A. E. (2008). The structural basis for mapping behavior onto the ventral striatum and its subdivisions. Brain Struct. Funct. 213, 17-27.

Meredith, G. E., Pennartz, C. M., and Groenewegen, H. J. (1993). The cellular framework for chemical signalling in the nucleus accumbens. Prog. Brain Res. 99, 3-24.
Moorman, D. E., and Aston-Jones, G. (2010). Orexin/hypocretin modulates response of ventral tegmental dopamine neurons to prefrontal activation: diurnal influences. J. Neurosci. 30, 15585-15599.

Mori, K., Kim, J., and Sasaki, K. (2011). Electrophysiological effects of orexin-B and dopamine on rat nucleus accumbens shell neurons in vitro. Peptides 32, 246-252.

Mulder, A. B., Hodenpijl, M. G., and Lopes da Silva, F. H. (1998). Electrophysiology of hippocampal and amygdaloid projections to the nucleus accumbens of the rat: convergence, segregation, and interaction of inputs. J. Neurosci. 18, 5095-5102.

Mukai, K., Kim, J., Nakajima, K., Oomura, Y., Wayner, M. J., and Sasaki, K. (2009). Electrophysiological effects of orexin/hypocretin on nucleus accumbens shell neurons in rats: an in vitro study. Peptides 30, 1487-1496.

Muschamp, J. W., Dominguez, J. M., Sato, S. M., Shen, R. Y., and Hull, E. M. (2007). A role for hypocretin (orexin) in male sexual behavior. J. Neurosci. 27, 2837-2845.

Narita, M., Nagumo, Y., Hashimoto, S., Narita, M., Khotib, J., Miyatake, M., et al. (2006). Direct involvement of orexinergic systems in the activation of the mesolimbic dopamine pathway and related behaviors induced by morphine. J. Neurosci. 26, 398-405.

Nauta, W. J., Smith, G. P., Faull, R. L., and Domesick, V. B. (1978). Efferent connections and nigral afferents of the nucleus accumbens septi in the rat. Neuroscience 3, 385-401.

O’Donnell, P., and Grace, A. A. (1995). Synaptic interactions among excitatory afferents to nucleus accumbens neurons: hippocampal gating of prefrontal cortical input. J. Neurosci. 15, 3622-3639.

Patel, J., Trout, S. J., and Kruk, Z. L. (1992). Regional differences in evoked dopamine efflux in brain slices of rat anterior and posterior caudate putamen. Naunyn Schmiedebergs Arch. Pharmacol. 346, 267-276.

Pennartz, C. M., Groenewegen, H. J., and Lopes da Silva, F. H. (1994). The nucleus accumbens as a complex of functionally distinct neuronal ensembles: an integration of behavioural, electrophysiological and anatomical data. Prog. Neurobiol. 42, 719-761.

Peyron, C., Tighe, D. K., van Den Pol, A. N., de Lecea, L., Heller, H. C., Sutcliffe, J. G., 
et al. (1998). Neurons containing hypocretin (orexin) project to multiple neuronal systems. J. Neurosci. 18, 9996-10015.

Phillips, P. E., Stuber, G. D., Heien, M. L., Wightman, R. M., and Carelli, R. M. (2003). Subsecond dopamine release promotes cocaine seeking. Nature 422, 614-618.

Rice, M. E., and Cragg, S. J. (2004). Nicotine amplifies reward-related dopamine signals in striatum. Nat. Neurosci. 7, 583-584.

Roitman, M. F., Stuber, G. D., Phillips, P. E., Wightman, R. M., and Carelli, R. M. (2004). Dopamine operates as a subsecond modulator of food seeking. J. Neurosci. 24, 1265-1271.

Sakurai, T., Amemiya, A., Ishii, M., Matsuzaki, I., Chemelli, R. M., Tanaka, H., et al. (1998). Orexins and orexin receptors: a family of hypothalamic neuropeptides and G protein-coupled receptors that regulate feeding behavior. Cell 92, 1.

Sesack, S. R., Deutch, A. Y., Roth, R. H., and Bunney, B. S. (1989). Topographical organization of the efferent projections of the medial prefrontal cortex in the rat: an anterograde tract-tracing study with Phaseolus vulgaris leucoagglutinin. J. Comp. Neurol. 290, 213-242.

Sesack, S. R., and Grace, A. A. (2010). Cortico-Basal Ganglia reward network: microcircuitry. Neuropsychopharmacology 35, 27-47.

Sesack, S. R., and Pickel, V. M. (1990). In the rat medial nucleus accumbens, hippocampal and catecholaminergic terminals converge on spiny neurons and are in apposition to each other. Brain Res. 527, 266-279.

Sesack, S. R., and Pickel, V. M. (1992). Prefrontal cortical efferents in the rat synapse on unlabeled neuronal targets of catecholamine terminals in the nucleus accumbens septi and on dopamine neurons in the ventral tegmental area. J. Comp. Neurol. 320, 145-160.

Stanley, E. M., and Fadel, J. R. (2011). Aging-related alterations in orexin/hypocretin modulation of septo-hippocampal amino acid neurotransmission. Neuroscience 195, 70-79.

Svensson, L., Zhang, J., Johannessen, K., and Engel, J. A. (1994). Effect of local infusion of glutamate analogues into the nucleus accumbens of rats: an electrochemical and behavioural study. Brain Res. 643, 155-161.

Thompson, J. L., and Borgland, S. L. (2011). A role for hypocretin/orexin in motivation. Behav. Brain Res. 217, 446-453.

Thorpe, A. J., and Kotz, C. M. (2005). Role of orexin receptors in the nucleus accumbens in dopamine-dependent turning behaviour of rats. Brain Res. 1050, 156-162.

Tsai, H. C., Zhang, F., Adamantidis, A., Stuber, G. D., Bonci, A., de Lecea, L., et al. (2009). Phasic firing in dopaminergic neurons is sufficient for behavioral conditioning. Science 324, 1080-1084.
Trivedi, P., Yu, H., MacNeil, D. J., Van der Ploeg, L. H., and Guan, X. M. (1998). Distribution of orexin receptor mRNA in the rat brain. FEBS Lett. 438 , 71-75.

Vittoz, N. M., and Berridge, C. W. (2006). Hypocretin/orexin selectively increases dopamine efflux within the prefrontal cortex: involvement of the ventral tegmental area. Neuropsychopharmacology 31, 384-395.

Vittoz, N. M., Schmeichel, B., and Berridge, C. W. (2008). Hypocretin /orexin preferentially activates caudomedial ventral tegmental area dopamine neurons. Eur. J. Neurosci. 28, 1629-1640.

Wang, H., and Pickel, V. M. (2002). Dopamine D2 receptors are present in prefrontal cortical afferents and their targets in patches of the rat caudate-putamen nucleus. J. Comp. Neurol. 442, 392-404.

Wang, B., You, Z. B., and Wise, R. A. (2009). Reinstatement of cocaine seeking by hypocretin (orexin) in the ventral tegmental area: independence from the local corticotropin-releasing factor network. Biol. Psychiatry 65, 857-862.

Wu, Y., Pearl, S. M., Zigmond, M. J., and Michael, A. C. (2000). Inhibitory glutamatergic regulation of evoked dopamine release in striatum. Neuroscience 96, 65-72.

Yorgason, J. T., Espana, R. A., and Jones, S. R. (2011). Demon voltammetry and analysis software: analysis of cocaine-induced alterations in dopamine signaling using multiple kinetic measures. J. Neurosci. Methods 202, 158-164.

Zhang, H., and Sulzer, D. (2003). Glutamate spillover in the striatum depresses dopaminergic transmission by activating group I metabotropic glutamate receptors. J. Neurosci. 23, 10585-10592.

Conflict of Interest Statement: The authors declare that the research was conducted in the absence of any commercial or financial relationships that could be construed as a potential conflict of interest.

Received: 15 September 2012; accepted: 05 November 2012; published online: 28 November 2012.

Citation: Patyal R, Woo EY and Borgland SL (2012) Local hypocretin-1 modulates terminal dopamine concentration in the nucleus accumbens shell. Front. Behav. Neurosci. 6:82. doi: 10.3389/fnbeh.2012.00082

Copyright (c) 2012 Patyal, Woo and Borgland. This is an open-access article distributed under the terms of the Creative Commons Attribution License, which permits use, distribution and reproduction in other forums, provided the original authors and source are credited and subject to any copyright notices concerning any third-party graphics etc. 